\title{
Inhibition by Sulfonamides of the
}

\section{Candidacidal Activity of Human Neutrophils}

\author{
ROBERT I. LEHRER \\ From the Cancer Research Institute and Department of Medicine, School of \\ Medicine, University of California, San Francisco, California 94122
}

\begin{abstract}
A B S T R A C T Sulfonamides reduced substantially the ability of normal human neutrophils to kill strains of Candida albicans and Candida tropicalis, and impaired to a lesser extent their activity against Staphylococcus aureus 502A and Serratia marcescens. Sulfonamides also inhibited $(a)$ iodination of Candida cells by normal neutrophils; $(b)$ candidacidal activity in cell-free systems containing purified human myeloperoxidase, hydrogen peroxide, and potassium iodide; and (c) accumulation of molecular iodine in analogously constructed cell-free systems. In contrast to these effects on reactions catalyzed by myeloperoxidase, sulfonamides exerted relatively little effect on the levels of microbicidal activity manifested by human neutrophils that lacked myeloperoxidase. Sulfonamides appear to influence the function of human neutrophils predominantly by interfering with myeloperoxidase-mediated pathways. Certain basic and clinical implications of these data are discussed.
\end{abstract}

\section{INTRODUCTION}

In recent studies, leukocytes from some patients with kidney transplants manifested an impaired ability to kill Candida albicans when tested in autologous serum, despite normal candidacidal activity if tested in normal serum. ${ }^{1}$ During serial studies of the leukocytes and serum of one such patient, this pattern of in vitro candidacidal activity appeared after the initiation of therapy with a sulfonamide. Experiments were then performed to determine whether sulfonamides influence leukocyte microbicidal function.

Presented in part at the annual meeting of the Ameriran Federation for Clinizal Research, Atlantic City, N. J., May 1970.

Received for publication 23 December 1970 and in revised form 14 June 1971.

${ }^{1}$ Lehrer, R. I., and S. Kountz. Unpublished observations.

\section{METHODS}

Patients. Myeloperoxidase-deficient leukocytes were obtained from two patients. C. J. B. is a $51 \mathrm{yr}$ old man with hereditary myeloperoxidase (MPO) deficiency; his case has been described in detail (1). The second patient $(H$. H.) was a $61 \mathrm{yr}$ old man with mosaic $\mathrm{MPO}^{2}$ deficiency associated with refractory megaloblastic anemia. ${ }^{8}$ At the time of these experiments, more than $99 \%$ of his neutrophils were completely deficient in peroxidase.

Leukocyte preparation. Blood was obtained from normal adult volunteers and from the two MPO-deficient subjects. $5 \mathrm{USP} \mathrm{U} / \mathrm{ml}$ of sodium heparin ${ }^{4}$ were added, and the red cells were sedimented by adding 1 volume of $3 \%$ dextran" in normal saline for each 2 volumes of blood. The leukocyte-rich supernatant was centrifuged at $150 \mathrm{~g}$ for $8 \mathrm{~min}$ at room temperature. The cells were suspended in Hanks' balanced salt solution (HBSS) containing $15 \%$ fetal calf serum and $5 \mathrm{U} / \mathrm{ml}$ of heparin, centrifuged again and suspended as above. Immediately before addition to the incubation mixtures, the leukocytes were centrifuged at $150 \mathrm{~g}$ for $8 \mathrm{~min}$ and suspended at the desired concentration in plain HBSS.

Microorganisms. The previously characterized $C$. albicans strain 820 (2) was grown in yeast phase in Sabouraud's $2 \%$ dextrose broth ${ }^{\circ}$ at $33^{\circ} \mathrm{C}$. Experiments requiring colony-count procedures were performed with 7 -day old cultures. Under these conditions, a colony-forming unit (CFU) had a mean of 1.8 yeast cells (range, 1.6-2.2). All other experiments employed 3- to 5-day old cultures. An isolate of $C$. tropicalis $^{7}$ was cultured in Sabouraud's broth for 2-5 days at $33^{\circ} \mathrm{C}$. The concentration of either Candida species was determined by counting suitable dilutions in a hemocytometer. Staphylococcus aureus strain

${ }^{2}$ Abbreviations used in this paper: CFU, colony-forming unit; HBSS, Hanks' balanced salt solution; MPO, myeloperoxidase.

${ }^{8}$ Lehrer, R. I., L. S. Goldberg, N. P. Rosenthal, and M. A. Apple. Refractory megaloblastic anemia with myeloperoxidase-deficient neutrophils. Ann. Intern. Med. In press.

"Riker Laboratories, Inc., Northridge. Calif.

${ }^{5}$ Clinical grade, mol wt 100,000-200,000, Nutritional Biochemicals Corp., Cleveland, Ohio.

- Difco Laboratories, Detroit, Mich.

${ }^{7}$ Generously provided by Dr. Seymour Klebanoff. 
502A and a chromogenic strain of Serratia marcescens were cultured overnight at $37^{\circ} \mathrm{C}$ in tryptic soy broth (Difco), washed with distilled water containing $0.01 \%$ gelatin (gel-water), and adjusted to the desired concentration spectrophotometrically.

Sulfonamides. Sulfonamides were obtained from the Pharmaceutical Service of this institution as anhydrous powders; they met USP or National Formulary (sulfathiazole) criteria for purity. Sodium sulfadiazine and sodium sulfacetimide were dissolved in HBSS. Sulfathiazole and sulfisoxazole were dissolved in a small amount of $0.1 \mathrm{~N}$ $\mathrm{NaOH}$, and diluted with $\mathrm{HBSS}$ to appropriate concentrations. Sulfonamide solutions to be used with intact leukocytes were adjusted to $\mathrm{pH} 7.4$ with $0.1 \mathrm{~N} \mathrm{HCl}$ and sterilized by passage through a Millipore filter, ${ }^{8}$ pore size $0.22 \mu$. Leukocytes and sulfonamides were incubated together for 30 min before bacteria or fungi were added. These experiments employed final concentrations of sulfonamides ranging from 5 to $100 \mathrm{mg} / 100 \mathrm{ml}$.

Candidacidal assays. The ability of leukocytes to kill C. albicans was measured in three ways: dye exclusion, specific stain, and colony count. In the dye-exclusion assay (2), equal numbers of neutrophils and Candida cells were incubated together at $37^{\circ} \mathrm{C}$ in $\mathrm{HBSS}$ containing $25 \%$ normal human group AB serum. After $60 \mathrm{~min}$ the leukocytes were lysed with sodium desoxycholate and methylens blue was added in a concentration that stained only nonviable $C$. albicans. The specific-stain method was based on analysis of the morphological and tinctorial changes of Candida ingested by neutrophils. In this test, the percentage of Candida cells within neutrophils that were "ghosts" (i.e. had not germinated and had lost their cytophilic basophilia by Giemsa stain) after $2.5 \mathrm{hr}$ of incubation was taken to indicate the percentage of ingested organisms killed and partially degraded by neutrophils (3). Preliminary experiments demonstrated that sulfonamides did not alter the staining properties of viable and nonviable Candida cells examined in the dye-exclusion and specific-stain assays.

In studies with the colony-count method, leukocytes were suspended in a final volume of $1 \mathrm{ml}$ of HBSS with 25 or $95 \%$ normal group AB serum; sodium sulfadiazine was added to certain tubes. In two colony-count experiments with $C$. albicans, a low ratio of organisms to leukocytes was used. In these tests, assay tubes contained $5 \times 10^{\circ}$ neutrophils and $2 \times 10^{5} \mathrm{CFU}$ of $C$. albicans. In all other colony-count studies with $C$. albicans and $C$. tropicalis assay tubes contained $5 \times 10^{6}$ neutrophils and $2 \times 10^{8} \mathrm{CFU}$ of the desired Candida species. Leukocyte-free control tubes contained Candida cells, serum, and HBSS, with or without sodium sulfadiazine. All tubes were prepared in duplicate; incubation and sampling techniques are described below.

Candida cells were added to all tubes after the other components had incubated together for $30 \mathrm{~min}$ at $37^{\circ} \mathrm{C}$ Immediately after the addition of Candida to a tube, the contents were thoroughly mixed and three $10 \mu \mathrm{l}$ samples were removed; each was diluted in $2.5 \mathrm{ml}$ of gel-water. $25 \mu 1$ of each dilution was spread over the surface of a Sabouraud's agar plate that was then incubated at $37^{\circ} \mathrm{C}$ for at least $24 \mathrm{hr}$ to permit colony development. Assay and control tubes were incubated at $37^{\circ} \mathrm{C}$ with rotation $(30 \mathrm{rpm})$. After 90 and $180 \mathrm{~min}$ of incubation, additional triplicate samples were taken from each tube and handled as above. Control tubes containing HBSS and serum, with

\footnotetext{
${ }^{8}$ Millipore Corporation, Bedford, Mass.
}

or without sulfadiazine, did not undergo any fall in colony counts during a $180 \mathrm{~min}$ incubation period with $C$. tropicalis, or during a $90 \mathrm{~min}$ period with $C$. albicans. The mean percentage of leukocytes that contained ingested Candida cells and the mean number of Candida cells ingested per phagocytic leukocyte was the same whether or not the tubes contained sulfonamide.

Bactericidal assays. Bactericidal activity was measured as previously described (4). Duplicate assay mixtures (in a final volume of $1 \mathrm{ml}$ of HBSS containing $10 \%$ normal group AB serum) contained $1 \times 10^{7}$ neutrophils, $2 \times 10^{6}$ to $4 \times 10^{\circ} \mathrm{CFU}$ of Staph. aureus $502 \mathrm{~A}$ or S. marcescens, and, where indicated, $1 \mathrm{mg}$ of sodium sulfadiazine. Neither organism was inhibited or killed by the concentrations of serum or sulfadiazine employed in these studies. Differential centrifugation (1) was used to estimate the extent of ingestion of Staph. aureus 502A in the presence or absence of sulfadiazine. After $15 \mathrm{~min}$ of incubation under these conditions, the assay tubes were centrifuged for 6 $\min$ at $50 \mathrm{~g}$, and the concentration of bacteria in the supernatant was determined by the usual procedure for colony counting.

Myeloperoxidase-linked candidacidal activity. The purified human $\mathrm{MPO}^{\circ}$ (5) used in these studies had an activity of $15,300 \mathrm{U} / \mathrm{mg}$ when assayed with orthodianisidine; calculations were made with the Worthington formula (6)

$\mathrm{U} / \mathrm{mg}=$

$$
\frac{\mathrm{A}_{400} / \mathrm{min}}{11.3 \times \mathrm{mg} \text { of enzyme } / \mathrm{ml} \text { of reaction mixture }} \text {. }
$$

Lysates from erythrocyte-free human peripheral blood leukocytes, prepared in $0.01 \mathrm{M}$ acetate buffer as previously described (1), provided an alternate source of peroxidase activity. Crystalline horseradish peroxidase, activity stated as 300 purpurogallin $\mathrm{U} / \mathrm{mg}$, was purchased from Sigma Chemical Company, St. Louis, Mo.

Candidacidal activity in a cell-free system was measured by minor modifications of a previously described method (7). All tubes contained sodium citrate-phosphate buffer $\mathrm{pH}$ 6.0, $40 \mu$ moles; $C$. albicans, $1 \times 10^{6} \mathrm{CFU}$; and sufficient distilled water to bring the final volume to $0.5 \mathrm{ml}$. Selected tubes also contained one or more of the following: MPO, $1.25 \mu \mathrm{g} ; \mathrm{KI}, 0.025,0.05$, or $0.125 \mu$ mole; $\mathrm{H}_{2} \mathrm{O}_{2}$, $0.05,0.125$, or $0.25 \mu$ mole; and sodium sulfacetimide, 0.5 $\mu$ mole, or sodium sulfadiazine, $0.18 \mu$ mole. $^{10}$ Sulfonamide solutions were adjusted to $\mathrm{pH} 6.0$ by addition of $0.1 \mathrm{M}$ citric acid. $\mathrm{H}_{2} \mathrm{O}_{2}$ was the last component to be added and the tubes were then incubated at $37^{\circ} \mathrm{C}$ for $60 \mathrm{~min}$ before samples were taken for colony count.

Peroxidase assays. Peroxidase activity was measured by the Worthington method with orthodianisidine as substrate (6), and by an iodometric method adapted from the macromethod of Davis (8). The latter assay was performed in tubes containing sodium citrate-phosphate buffer $(\mathrm{pH}$ 5.0 or 5.6), $50 \mu$ moles; $\mathrm{KI}, 1 \mu$ mole; $\mathrm{H}_{2} \mathrm{O}_{2}, 1 \mu$ mole; sodium thiosulfate, $10-50$ nmoles; enzyme ( $1 \mu \mathrm{g}$ of MPO or an approximately equiactive quantity of leukocyte lysate); boiled starch, $0.1 \%$; and distilled water to bring the final volume to $1 \mathrm{ml}$. Sulfonamide solutions to be tested were adjusted to the appropriate $\mathrm{pH}$ with $0.1 \mathrm{~m}$ citric acid. The reaction was started by adding $\mathrm{H}_{2} \mathrm{O}_{2}$ and the number of seconds that elapsed before the sudden appearance of a

\footnotetext{
${ }^{9}$ Generously provided by Dr. Julius Schultz.

${ }^{10}$ These concentrations correspond to $20 \mathrm{mg} / 100 \mathrm{ml}$ of sodium sulfacetimide and $10 \mathrm{mg} / 100 \mathrm{ml}$ of sodium sulfadiazine.
} 
TABLE I

Inhibition of Leukocyte Candidacidal Activity by Sulfonamides

\begin{tabular}{ccccc}
\hline & \multicolumn{4}{c}{$\begin{array}{c}\text { Leukocyte candidacidal activity (per cent of control*) } \\
\text { in the presence of }\end{array}$} \\
\cline { 2 - 5 } $\begin{array}{c}\text { Sulfonamide } \\
\text { concen- } \\
\text { tration }\end{array}$ & $\begin{array}{c}\text { Sulfadiazine } \\
\text { (5 subjects) }\end{array}$ & $\begin{array}{c}\text { Sulfathiazole } \\
\text { (4 subjects) }\end{array}$ & $\begin{array}{c}\text { Sulfisoxazole } \\
\text { (4 subjects) }\end{array}$ & $\begin{array}{c}\text { Sulfacetimide } \\
\text { (3 subjects) }\end{array}$ \\
\hline$m g / 100 m l$ & 100 & 100 & 100 & 100 \\
0 (control) & $78.9 \pm 6.3$ & $67.6 \pm 10.5$ & $87.4 \pm 10.9$ & $64.1 \pm 3.8$ \\
5 & $56.5 \pm 6.3$ & $48.4 \pm 14.5$ & $55.6 \pm 8.8$ & $65.7 \pm 2.3$ \\
10 & $28.0 \pm 4.9$ & $13.5 \pm 9.5$ & $19.0 \pm 6.5$ & $29.8 \pm 10.0$ \\
25 & $10.5 \pm 4.4$ & NT $\ddagger$ & NT & NT \\
50 & & & &
\end{tabular}

* This figure was derived by dividing the percentage of $C$. albicans killed by a subject's leukocytes in the presence of sulfonamide by the percentage killed by these leukocytes in the absence of sulfonamide (control) $\times 100$. Data are expressed as mean \pm SEM. Candidacidal activity was measured by the dye-exclusion assay.

$\ddagger N T$, not tested.

blue color (denoting the molecular iodine-starch complex) was recorded. The time, in seconds, to reach the endpoint was inversely proportional to the enzyme concentration and directly proportional to the thiosulfate concentration and indicated the time required to generate iodine in excess of the reducing capacity of the thiosulfate. In a given study, a concentration of thiosulfate was selected that gave an endpoint at approximately $5 \mathrm{sec}$ in the absence of inhibitors.

Quantitative iodination. The ability of normal human neutrophils to iodinate $C$. albicans was studied by slight modifications of the method of Pincus and Klebanoff (9). Incubation mixtures contained $10^{7}$ peripheral blood leukocytes, $2.5 \times 10^{7}$ heat-killed $C$. albicans, 10 nmoles of $\mathrm{KI}$, and $0.2 \mu \mathrm{Ci}$ of carrier free $\left[{ }^{181} \mathrm{I}\right] \mathrm{NaI}^{11}$ in a final volume of $0.5 \mathrm{ml}$ of HBSS containing $10 \%$ normal group AB serum. Sodium sulfadiazine or sodium azide was added to selected tubes. In some studies, zymosan ${ }^{12}$ replaced heatkilled $C$. albicans; in some, calcium-free Krebs-Ringer phosphate buffer (10) replaced HBSS. All assay components were adjusted to a $\mathrm{pH}$ of 7.4 before addition to incubation mixtures. Tubes were incubated for $60 \mathrm{~min}$ at $37^{\circ} \mathrm{C}$ and processed as described (9).

\section{RESULTS}

Candida albicans. Normal human neutrophils, tested by the dye-exclusion assay, kill approximately one-third of ingested $C$. albicans, strain 820 , in $1 \mathrm{hr}(1,2)$. Sulfadiazine, sulfathiazole, sulfisoxazole, and sulfacetimide all diminished the candidacidal activity of normal neutrophils; the extent of inhibition was dependent on the concentration of sulfonamide in the incubation mixture (Table I). This inhibition was not caused by a decrease in ingestion of the organism. Microscopic examination of unstained wet preparations and of fixed and stained slides prepared $15 \mathrm{~min}$ after addition of $C$. albicans cells to the incubation mixtures revealed that all of the added

\footnotetext{
${ }^{11}$ New England Nuclear Corp., Boston, Mass.

${ }^{12}$ Schwarz/Mann, Orangeburg, N. Y.
}

organisms were ingested at every concentration of sulfonamide tested.

Equal and virtually complete inhibition resulted whether cells were preincubated with sulfadiazine (50 $\mathrm{mg} / 100 \mathrm{ml}$ ) for 1,15 , or $30 \mathrm{~min}$ before the addition of fungi. This same concentration of sulfadiazine, added to normal leukocytes $15 \mathrm{~min}$ after addition of Candida, resulted in only about half of the potential inhibitory effect. If the addition of sulfadiazine was delayed until $30 \mathrm{~min}$ after the addition of Candida, killing was inhibited by only $20 \%$. Leukocytes preincubated with sulfadiazine and washed free of the drug killed $C$. albicans normally. These observations suggest that magnitude of the inhibitory effect was determined primarily by the concentration of sulfonamide present during the early postphagocytic period.

In addition to these dye-exclusion studies, candidacidal activity was also measured by a standard colony-count technique and by the specific staining assay. Whether the criterion of candidacidal effectiveness was the percentage of $C$. albicans cells stained by $2 \times 10^{-4}$ methylene blue (dye exclusion), the percentage fall from initial colonycount levels, or the percentage of organisms within neutrophils that were "ghosts" (specific stain), sulfadiazine inhibited the normal candidacidal activity of neutrophils. At a concentration of $100 \mathrm{mg} / 100 \mathrm{ml}$, this inhibition was shown to be essentially complete by all test systems ( $\mathrm{Ta}$ ble II). In the two colony-count studies conducted at

\section{TABLE II}

Comparison of Three Methods of Demonstrating the Ability of Sulfonamides to Inhibit the Killing of C. albicans by Normal Neutrophils*

\begin{tabular}{lcccc}
\hline Assay method & Serum & $\begin{array}{c}\text { Neutro- } \\
\text { phils }\end{array}$ & $\begin{array}{c}\text { Sulfa- } \\
\text { diazine }\end{array}$ & $\begin{array}{c}\text { "Nonviable" } \\
\text { C. albicans }\end{array}$ \\
\hline Dye exclusion, & & & $m g / 100 \mathrm{ml}$ & $\%$ \\
60 min & + & + & 0 & 42.3 \\
& + & + & 5 & 38.3 \\
& + & + & 10 & 32.7 \\
& + & + & 25 & 16.8 \\
& + & + & 50 & 9.3 \\
& + & + & 100 & 0.3
\end{tabular}

Colony-count,

$90 \mathrm{~min}$

$\begin{array}{rrrr}+ & + & 0 & 61.5 \\ + & + & 100 & 10.8 \\ + & 0 & 0 & 10.8\end{array}$

Specific stain,
150 min

$\begin{array}{rrrr}+ & + & 0 & 44.5 \\ + & + & 100 & 3.0\end{array}$

* The experimental conditions and criteria for determining candidacidal activity are described in the text. + , presence of component; 0 , its absence. The data are the results of a single experiment on leukocytes from a normal subject. 
TABLE III

Effect of Sulfadiazine and Serum on the Ability of Normal Human Neutrophils to Kill C. albicans*

\begin{tabular}{|c|c|c|c|c|c|c|c|}
\hline \multirow[b]{3}{*}{ Incubation medium } & & \multicolumn{4}{|c|}{ Specific stain assay } & \multirow{2}{*}{\multicolumn{2}{|c|}{$\frac{\text { Colony-count assay }}{\begin{array}{c}\text { Colony-count } \\
\text { reduction }\end{array}}$}} \\
\hline & & \multicolumn{2}{|c|}{$\begin{array}{l}\text { Ghosts in } \\
\text { neutrophils }\end{array}$} & \multicolumn{2}{|c|}{$\begin{array}{l}\text { Germination in } \\
\text { neutrophils }\end{array}$} & & \\
\hline & & $150 \mathrm{~min}$ & $240 \mathrm{~min}$ & $150 \mathrm{~min}$ & $240 \mathrm{~min}$ & $90 \mathrm{~min}$ & $180 \mathrm{~min}$ \\
\hline & & \multicolumn{2}{|c|}{$\%$} & \multicolumn{2}{|c|}{$\%$} & \multicolumn{2}{|c|}{$\%$} \\
\hline \multirow[t]{2}{*}{ I $25 \%$ serum } & Mean & 43.9 & 43.0 & 7.6 & 27.9 & 42.9 & 49.1 \\
\hline & SEM & 2.8 & 2.8 & 2.0 & 2.3 & 3.8 & 4.4 \\
\hline \multirow[t]{2}{*}{ II $95 \%$ serum } & Mean & 17.1 & 18.6 & 19.4 & 58.7 & 23.1 & 20.0 \\
\hline & SEM & 3.4 & 3.3 & 3.1 & 3.6 & 4.5 & 5.7 \\
\hline \multirow{2}{*}{$\begin{array}{l}\text { III } 95 \% \text { serum plus sulfadiazine } \\
(25 \mathrm{mg} / 100 \mathrm{ml})\end{array}$} & Mean & 8.8 & 6.8 & 22.6 & 74.5 & 16.8 & 13.4 \\
\hline & SEM & 2.2 & 1.7 & 4.2 & 3.7 & 3.4 & 5.9 \\
\hline Null hypothesis & \multicolumn{7}{|c|}{ Statistical significance, paired $t$ test } \\
\hline$I=I I$ & $P$ & $<0.001$ & $<0.001$ & $<0.001$ & $<0.001$ & $<0.01$ & $<0.001$ \\
\hline$I=I I I$ & $P$ & $<0.001$ & $<0.001$ & $<0.005$ & $<0.001$ & $<0.005$ & $<0.005$ \\
\hline $\mathrm{II}=\mathrm{III}$ & $P$ & $<0.005$ & $<0.005$ & NS $\ddagger$ & $<0.005$ & NS & NS \\
\hline
\end{tabular}

* Data represent six experiments on leukocytes from different normal subjects. The rate and extent of ingestion was comparable in all tubes.

$\ddagger \mathrm{NS}, P>0.05$.

very low ratios of Candida to leukocytes, normal leukocytes effected a $59.1 \%$ (mean) fall in colony count at 90 min in HBSS and a $10.4 \%$ fall in HBSS with sodium sulfadiazine $(100 \mathrm{mg} / 100 \mathrm{ml})$.

Candidacidal activity was measured by both colony count and by specific-stain technique in a series of six experiments undertaken to examine the effect of moderate concentrations of sulfadiazine on neutrophil function in media with high concentrations of serum. Without sulfadiazine, neutrophil candidacidal activity was more than twice as effective in medium containing $25 \%$ serum than in otherwise identical medium containing $95 \%$ serum (Table III). The ability of neutrophils to kill ingested C. albicans in medium containing $95 \%$ serum was further curtailed by the presence of $25 \mathrm{mg}$ of sodium sulfadiazine per $100 \mathrm{ml}$. This was most clearly shown by a greater than $50 \%$ decrease in the percentage of Candida within sulfadiazine-treated neutrophils that were "ghosts" after 150 and $240 \mathrm{~min}$ of incubation. The inhibitory effect of sulfadiazine on neutrophil function was also shown by the increased ability of $C$. albicans to form pseudogerm tubes after $240 \mathrm{~min}$ of intracellular residence in sulfadiazine-treated neutrophils. Although the colonycount data also suggest that $25 \mathrm{mg} / 100 \mathrm{ml}$ of sulfadiazine depress the candidacidal activity of leukocytes in 95\% serum, the results with this technique were more variable and the differences did not achieve statistical significance.

Candida tropicalis. A strain of $C$. tropicalis killed, albeit slowly, by the MPO-deficient neutrophils of patient
C.J.B. (11) was used in an attempt to elucidate the mechanism of inhibition by sulfonamides. If the effect of sulfonamides resulted solely from interference with the MPO-mediated candidacidal mechanisms of neutrophils, MPO-deficient neutrophils should not be affected by sulfonamides. On the other hand, if sulfonamides inhibited microbicidal components unrelated to MPO, these drugs should also inhibit MPO-deficient neutrophils. These propositions were tested in five experiments wherein
NORMAL LEUKOCYTES

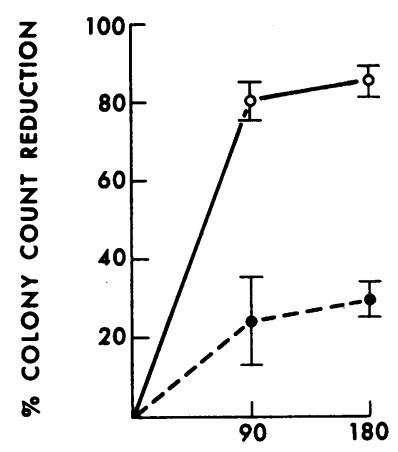

INCUBATION TIME (MIN)
MPO-DEFICIENT LEUKOCYTES

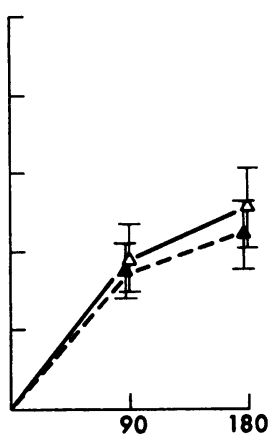

Figure 1 Effect of sulfadiazine, $100 \mathrm{mg} / 100 \mathrm{ml}$, on the ability of normal and MPO-deficient leukocytes (patient C. J. B.) to kill $C$. tropicalis. $\bigcirc$ and $\Delta$, in the absence of sulfadiazine; $\boldsymbol{C}$ and $\boldsymbol{\Delta}$, in the presence of sulfadiazine; vertical bar represents \pm 1 SEM. Four paired experiments were done by using leukocytes from a different normal subject in each. 
Staphylococcus aureus 502A

Serratia marcescens
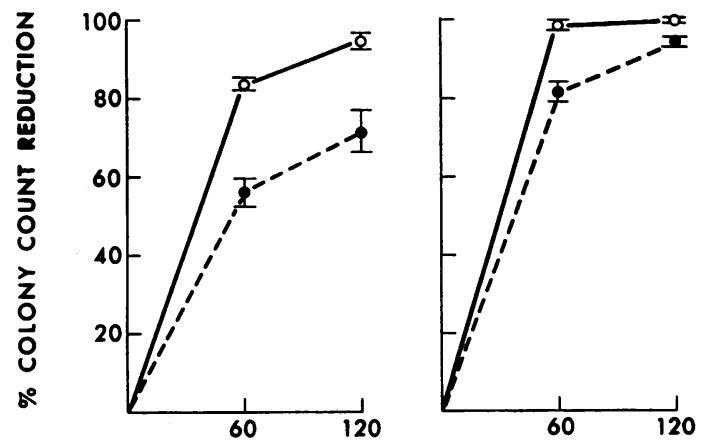

INCUBATION TIME (MIN)

FIGURE 2 Effect of sulfadiazine on bactericidal activity of normal leukocytes. $O$, in the absence of drug; $\bullet$, in the presence of sodium sulfadiazine, $100 \mathrm{mg} / 100 \mathrm{ml}$; vertical bar represents SEM of percentage of colony-count reduction within this representative experiment.

leukocytes from different normal subjects were compared with those from the MPO-deficient subjects C. J. B. (four experiments) and H. H. (one experiment) in the presence and absence of sodium sulfadiazine $(100 \mathrm{mg} /$ $100 \mathrm{ml}$ ).

In the absence of sulfonamides, C. J. B.'s MPO-deficient neutrophils killed $C$. tropicalis less effectively than did normal cells (90 min, $P<0.025 ; 180 \mathrm{~min}, P<$ 0.05 ) (Fig. 1). Similar results were obtained with leukocytes from $\mathrm{H}$. H. (not shown). Sulfadiazine $(100 \mathrm{mg} /$ $100 \mathrm{ml}$ ) greatly inhibited the candidacidal activity of normal leukocytes (90 min, $P<0.025 ; 180 \mathrm{~min}, P<$ 0.01 ); however, it had a considerably smaller effect on the neutrophils of C. J. B. $(90 \mathrm{~min}, P>0.2 ; 180 \mathrm{~min}$, $P<0.05)$, and did not inhibit those of $\mathrm{H}$. H. These findings are consistent with the hypothesis that sulfonamides exert their inhibitory effect predominantly through interference with MPO-dependent mechanisms. In the presence of sulfadiazine, MPO-deficient (C. J. B.) and normal neutrophils did not differ significantly in their ability to kill $C$. tropicalis ( $90 \mathrm{~min}, P>0.20 ; 180 \mathrm{~min}$, $P>0.05$ ), although the number of experiments is too small to exclude the possibility that such a difference exists.

Bactericidal activity. In light of previous studies suggesting that MPO promotes the killing of Staph. aureus $502 \mathrm{~A}$ and $S$. marcescens by normal neutrophils (4), it was of interest to examine the effect of sulfonamides on the ability of neutrophils to kill these organisms. At a concentration of $100 \mathrm{mg} / 100 \mathrm{ml}$, sodium sulfadiazine consistently decreased the rate at which these organisms were killed by normal neutrophils (Fig. 2). Ingestion, as estimated by differential centrifugation, was unimpaired. In a study comparing the effects of sulfadiazine on the staphylocidal activity of normal and MPO-deficient neutrophils (C. J. B.), the MPO-deficient cells, unlike normal leukocytes, were only slightly inhibited (Fig. 3). It is noteworthy that, even in the presence of sulfadiazine, normal leukocytes killed staphylococci more effectively than did MPO-deficient cells.

MPO-linked candidacidal activity. The above data suggest that the inhibition of microbicidal activity by sulfonamides arises from interference with the neutrophil's MPO-linked intracellular mechanisms. A system composed of $\mathrm{MPO}, \mathrm{H}_{2} \mathrm{O}_{2}$, and $\mathrm{KI}$ has been proposed as a model of the neutrophil microbicidal system $(12,13)$; this system kills Candida species in vitro (7). The possibility that sulfonamides might inhibit this system was examined in a series of experiments with $C$. albicans.

Potassium iodide was tested at concentrations ranging from $2.5 \times 10^{-4} \mathrm{M}$ to $5 \times 10^{-5} \mathrm{M}$, and $\mathrm{H}_{2} \mathrm{O}_{2}$ was used at concentrations between $5 \times 10^{-4} \mathrm{M}$ and $1 \times 10^{-4} \mathrm{M}$. C. albicans was not killed when MPO, KI, and $\mathrm{H}_{2} \mathrm{O}_{2}$ were added singly or in combinations of two to the incubated material, or when the lowest concentrations of both $\mathrm{KI}$ and $\mathrm{H}_{2} \mathrm{O}_{2}$ were combined with MPO. Of the 12 trials (within three large experiments) wherein all three reactants were combined, effective candidacidal activity resulted in 10 . When sulfonamides were added to combinations of reactants that induced a greater than $99 \%$ fall in the colony count, they inhibited candidacidal activity in only two of five trials. In contrast, when added to combinations of reactants that decreased the number of viable colonies by 40 to $99 \%$, sulfonamides inhibited the candidacidal activity in five of five trials. Three

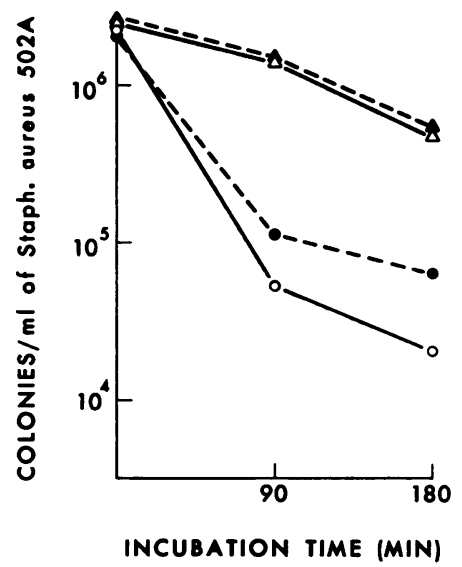

Figure 3 Effect of sulfadiazine, $100 \mathrm{mg} / 100 \mathrm{ml}$, on the ability of normal and MPO-deficient leukocytes to kill Staph. aureus 502A. Colony counts are plotted on a logarithmic scale. Rate of ingestion, as determined by differential centrifugation, was unaltered by sulfadiazine. $\triangle$ and $\Delta$, MPO-deficient leukocytes from patient C. J. B.; $\bigcirc$ and -, simultaneously tested normal leukocytes; solid circles and triangles indicate the presence of sulfadiazine. 
such trials, from two separate experiments, are shown in Table IV.

Peroxidase activity. Even in extremely high concentration $(500 \mathrm{mg} / 100 \mathrm{ml})$, sulfacetimide did not inhibit the rate of oxidation of orthodianisidine by purified human MPO, leukocyte lysates, or horseradish peroxidase. In contrast, low concentrations of all sulfonamides tested inhibited the rate of accumulation of molecular iodine in a system containing leukocyte lysate (or purified MPO), $\mathrm{H}_{2} \mathrm{O}_{2}$, and $\mathrm{KI}$ (Table V).

Quantitative iodination. Sulfadiazine inhibited the iodination of heat-killed $C$. albicans after their ingestion by normal leukocytes (Table VI). The magnitude of inhibition was dependent on the concentration of sulfonamide and broadly paralleled the inhibition of candidacidal activity as measured by the dye-exclusion assay (Table I). Almost identical levels of iodination were observed when zymosan $(0.5 \mathrm{mg})$ replaced the heat-killed $C$. albicans in these tests, and an equivalent reduction of iodination attended the inclusion of sulfadiazine $(100 \mathrm{mg} / 100$ $\mathrm{ml})$ under these conditions as well. Iodination and its inhibition by sulfonamides were also observed when $C$. albicans or zymosan was ingested by leukocytes in KrebsRinger phosphate buffer, but both processes occurred with somewhat reduced efficiency relative to their levels

\section{TABLE IV}

Effect of Sulfonamides on a Myeloperoxidase-Iodide-Hydrogen Peroxide Candidacidal System

\begin{tabular}{|c|c|c|c|c|}
\hline MPO & $\mathbf{K I}$ & $\mathrm{H}_{2} \mathrm{O}_{2}$ & Sulfonamide & C. albicans \\
\hline & & & & colonies $/ m l$ \\
\hline \multicolumn{5}{|c|}{ Experiment I } \\
\hline $0 *$ & 0 & 0 & 0 & $1.9 \times 10^{6}$ \\
\hline+ & 0 & 0 & 0 & $1.8 \times 10^{6}$ \\
\hline 0 & $2.5 \times 10^{-4} \mathrm{M}$ & 0 & 0 & $2.0 \times 10^{6}$ \\
\hline 0 & 0 & $5 \times 10^{-4} \mathrm{M}$ & 0 & $1.7 \times 10^{6}$ \\
\hline 0 & $2.5 \times 10^{-4} \mathrm{M}$ & $5 \times 10^{-4} \mathrm{M}$ & 0 & $1.7 \times 10^{6}$ \\
\hline+ & $2.5 \times 10^{-4} \mathrm{M}$ & 0 & 0 & $1.9 \times 10^{6}$ \\
\hline+ & 0 & $5 \times 10^{-4} \mathrm{M}$ & 0 & $1.7 \times 10^{6}$ \\
\hline+ & $1 \times 10^{-4} \mathrm{M}$ & $5 \times 10^{-4} \mathrm{M}$ & 0 & $2.2 \times 10^{5}$ \\
\hline+ & $1 \times 10^{-4} \mathrm{M}$ & $5 \times 10^{-4} \mathrm{M}$ & Sulfacetimide $\ddagger$ & $1.4 \times 10^{6}$ \\
\hline+ & $1 \times 10^{-4} \mathrm{M}$ & $5 \times 10^{-4} \mathrm{M}$ & Sulfadiazine§ & $1.4 \times 10^{6}$ \\
\hline \multicolumn{5}{|c|}{ Experiment II } \\
\hline 0 & 0 & 0 & 0 & $2.6 \times 10^{6}$ \\
\hline+ & 0 & 0 & 0 & $2.8 \times 10^{6}$ \\
\hline 0 & $1 \times 10^{-4} \mathrm{M}$ & 0 & 0 & $2.6 \times 10^{6}$ \\
\hline 0 & 0 & $2.5 \times 10^{-4} \mathrm{M}$ & 0 & $2.5 \times 10^{6}$ \\
\hline 0 & $1 \times 10^{-4} \mathrm{M}$ & $2.5 \times 10^{-4} \mathrm{M}$ & 0 & $2.5 \times 10^{6}$ \\
\hline+ & $1 \times 10^{-4} \mathrm{M}$ & 0 & 0 & $2.8 \times 10^{6}$ \\
\hline+ & 0 & $2.5 \times 10^{-4} \mathrm{M}$ & 0 & $2.3 \times 10^{6}$ \\
\hline+ & $5 \times 10^{-5} \mathrm{M}$ & $2.5 \times 10^{-4} \mathrm{M}$ & 0 & $7.7 \times 10^{5}$ \\
\hline+ & $5 \times 10^{-5} \mathrm{M}$ & $2.5 \times 10^{-4} \mathrm{M}$ & Sulfacetimide $f$ & $2.3 \times 10^{6}$ \\
\hline+ & $5 \times 10^{-5} \mathrm{M}$ & $2.5 \times 10^{-4} \mathrm{M}$ & Sulfadiazine & $1.9 \times 10^{6}$ \\
\hline+ & $5 \times 10^{-6} \mathrm{M}$ & $1 \times 10^{-4} \mathrm{M}$ & 0 & $2.6 \times 10^{4}$ \\
\hline+ & $5 \times 10^{-5} \mathrm{M}$ & $1 \times 10^{-4} \mathrm{M}$ & Sulfacetimide $\ddagger$ & $2.3 \times 10^{6}$ \\
\hline+ & $5 \times 10^{-5} \mathrm{M}$ & $1 \times 10^{-4} \mathrm{M}$ & Sulfadiazine & $1.5 \times 10^{8}$ \\
\hline
\end{tabular}

* + , the presence of a reactant $; 0$, its absence.

$\ddagger 20 \mathrm{mg} / 100 \mathrm{ml}\left(1 \times 10^{-3} \mathrm{M}\right)$.

$\$ 10 \mathrm{mg} / 100 \mathrm{ml}\left(3.7 \times 10^{-1} \mathrm{M}\right)$.
TABLE V

Inhibition by Sulfonamides oj Peroxidase-Catalyzed Iodine Accumulation from $\mathrm{H}_{2} \mathrm{O}_{2}$ and $\mathrm{KI}$

\begin{tabular}{crcccccc}
\hline \multicolumn{2}{c}{ Sulfisoxazole } & \multicolumn{2}{c}{ Sulfathiazole } & \multicolumn{2}{c}{$\begin{array}{c}\text { Sodium } \\
\text { sulfadiazine }\end{array}$} & \multicolumn{2}{c}{$\begin{array}{c}\text { Sodium } \\
\text { sulfacetimide }\end{array}$} \\
\hline nmoles* & sec $¥$ & nmoles & sec & nmoles & sec & nmoles & sec \\
0 & 5.2 & 0 & 5.2 & 0 & 5.2 & 0 & 5.2 \\
12.4 & 7.6 & 13 & 7.9 & 30.5 & 6.3 & 41 & 6.5 \\
31 & 10.5 & 32.5 & 14.1 & 61 & 9.8 & 82 & 9.1 \\
62 & 19.9 & 65 & 21.7 & 1228 & 13.8 & 1638 & 16.1 \\
1248 & 37.5 & $130 \S$ & 60.8 & 183 & 25.2 & NT & NT \\
\hline
\end{tabular}

* nmoles of the indicated sulfonamides in $1 \mathrm{ml}$ of reaction mixture contain ing 25 nmoles of sodium thiosulfate, $10 \mu \mathrm{l}$ of leukocyte lysate and other components as described in the text. $\mathrm{pH}$ was 5.0.

¥ Mean time elapsed to development of blue color.

$\$$ Sulfonamide concentration, $3.3 \mathrm{mg} / 100 \mathrm{ml}$.

in HBSS. Sodium azide ( $2 \mathrm{~mm}$ ) was a more effective inhibitor of iodination than the highest concentration of sulfonamide tested in these studies. Additional studies of these reactions are in progress.

\section{DISCUSSION}

After ingestion by mammalian leukocytes, bacteria and fungi are exposed to conditions within the phagocytic vacuole that can result in the death of many of these microorganisms. One of the microbicidal systems of neutrophils and monocytes involves the granulc enzyme, myeloperoxidase, and its oxidant substrate, hydrogen peroxide $(1,12)$. Klebanoff has recently advanced evidence suggesting that this may be the major microbicidal effector of the human neutrophil (11).

The evidence reported here indicates that sulfonamides

TABLE VI

Inhibition of Iodination of Heat-Killed C. albicans by Suljonamides

\begin{tabular}{lcc}
\hline \multicolumn{1}{c}{ Inhibitor } & Concentration & Iodination \\
\hline & & \% of control* \\
None & - & $100 \ddagger$ \\
Sulfadiazine & $5 \mathrm{mg} / 100 \mathrm{ml}$ & $78.9 \pm 5.3$ \\
Sulfadiazine & $10 \mathrm{mg} / 100 \mathrm{ml}$ & $61.0 \pm 4.4$ \\
Sulfadiazine & $25 \mathrm{mg} / 100 \mathrm{ml}$ & $41.1 \pm 3.1$ \\
Sulfadiazine & $50 \mathrm{mg} / 100 \mathrm{ml}$ & $23.8 \pm 1.8$ \\
Sulfadiazine & $100 \mathrm{mg} / 100 \mathrm{ml}$ & $11.2 \pm 0.9$ \\
Sodium azide & $2 \mathrm{mM}$ & $2.2 \pm 0.3$
\end{tabular}

* This figure was derived by dividing the mean number of acid-precipitable counts measured in the presence of the indicated inhibitor by the mean number of acid-precipitable counts measured in paired control tubes that lacked added inhibitors (mean \pm SEM, $n=4$ ).

$\ddagger$ Normal leukocytes fixed $4.43 \pm 0.38$ nmoles of iodide per $1 \times 10^{7}$ leukocytes into an acid-precipitable form under the conditions of these experiments (mean \pm SEM, $n=5$ ). 
can decrease the ability of normal human neutrophils to kill $C$. albicans, $C$. tropicalis, and, to a lesser extent, certain bacteria. Several features of these data suggest that the inhibitory effect arises from a relatively specific interference with the peroxidase-mediated microbicidal pathways of the neutrophil. Sulfonamides were found to inhibit the iodination of ingested $C$. albicans by intact normal leukocytes, a reaction shown by Klebanoff to be catalyzed by MPO $(9,12)$. The drugs inhibited the candidacidal activity of an in vitro system containing MPO, $\mathrm{H}_{2} \mathrm{O}_{2}$, and iodide, and also interfered with accumulation of iodine in this system. In contrast, sulfonamides exerted little effect on the microbicidal activity of MPO-deficient human neutrophils.

In vitro, MPO requires $\mathrm{H}_{2} \mathrm{O}_{2}$ and an additional cofactor, such as iodide or chloride, to exert maximally effective bactericidal $(12,13)$ and fungicidal (7) activity. When iodide is employed as the cofactor in cellfree systems, or is added to mixtures containing phagocytic leukocytes and appropriately opsonized microorganisms, the microorganisms are iodinated as well as killed $(9,12)$. The identity of the halide or halide-like cofactor presumed to operate under physiologic conditions in the intact human neutrophil has not been established with certainty $(12,14)$.

Two general classes of chemical compounds, peroxidase inhibitors and reducing agents, have been found to inhibit the bactericidal activity of $\mathrm{MPO}-\mathrm{H}_{2} \mathrm{O}_{2}$-halide systems. Cyanide and azide ions typify the former class of compounds. Cysteine, reduced glutathione, thiosulfate, and certain compounds with antithyroid activity such as thiourea, thiocyanate, and 1-methyl-2-mercaptoimidazole (Tapazole) $)^{\mathbf{1 3}}$ are included among the latter $(12,13,15)$. Most classes of antithyroid substances are either competitive substrates or inhibitors of various peroxidases (16); it is interesting to recall that sulfonamides also have antithyroid properties and are goitrogenic in rats (17). Possibly, the ability of sulfonamides to inhibit the function both of leukocytes and of thyroid cells shares a common biochemical basis: interference with peroxidasemediated reactions involving halide ions.

Although sulfonamides have been reported to inhibit the activity of certain plant peroxidases (18-20), activity of MPO per se (orthoanisidine assay) was not inhibited by sulfacetimide or sulfadiazine under or r experimental conditions. However, other mechanisms could account for the effects of sulfonamides on intracellular iodination and iodine accumulation. For example, sulfonamides could react with intermediate or final products generated by the MPO- $\mathrm{H}_{2} \mathrm{O}_{2}$-iodide system. The apparent inhibition of peroxidase activity by various thiols in iodometric assays is a well-recognized model of such an occurrence (21). Another possibility is that MPO could

${ }^{13}$ Eli Lilly and Company, Indianapolis, Ind. catalyze the oxidation of sulfonamides in the presence of $\mathrm{H}_{2} \mathrm{O}_{2}$ and iodide. In their studies on the inhibition of horseradish peroxidase by isonicotinic acid hydrazide, Andrejew, Gernez-Rieux, and Tacquet (22) noted appreciable peroxidase-catalyzed oxidation of that compound. Perhaps further elucidation of the precise mode of action of sulfonamides and other compounds (compounds that, while not peroxidase inhibitors, can inhibit the peroxidase-mediated antimicrobial activity of intact leukocytes) will facilitate the identification of the physiologic cofactor (s) for $\mathrm{H}_{2} \mathrm{O}_{2}$ in the MPO-catalyzed antimicrobial activity of the human neutrophil.

As therapeutic doses of sulfonamides regularly produce concentrations that would result in partial inhibition of candidacidal activity by normal neutrophils, it is necessary to consider whether this effect ever attains clinical significance. Many years of clinical use have produced no evidence to suggest that conventional doses of sulfonamides administered to otherwise normal subjects significantly increase their risk of developing systemic Candida infection.

However, systemic candidiasis typically affects, not otherwise normal patients, but persons with serious underlying disorders: recipients of renal transplants (23) and patients with acute leukemia or other neoplasms $(24,25)$. Such high-risk patients often receive treatment with many drugs, including those with immunosuppressive, antiinflammatory, cytotoxic, and antibiotic actions. These patients undoubtedly have sustained multiple breaches in their antifungal defense mechanisms and are exposed to additional factors that may increase the risk of opportunistic infection. What is the effect of sulfonamide therapy on resistance to Candida infection in this group? This question cannot be answered either from available clinical information or by extrapolation from experience with relatively normal patients. It may be that patients with other impaired host defenses are more dependent on intact function of their phagocytic leukocytes to maintain adequate over-all resistance to Candida infection $(25,26)$. If this were so, sulfonamides (or other drugs with comparable actions on leukocyte function) might have substantially greater effects on the over-all resistance of this group of patients than could be surmised from their effects on otherwise normal patients.

That sulfonamides impair the resistance of certain groups of patients to systemic candidiasis remains to be proved. Until the question is resolved by appropriate clinical studies, sulfonamides should not be prescribed unnecessarily to patients at high risk of developing this infection by virtue of other underlying conditions. If their use is required in such patients, appropriate monitoring can prevent the development of excessive serum concentrations and the attendant inimical effects on leukocyte function. 


\section{ACKNOWLEDGMENTS}

I thank Dr. Henry R. Bourne, Dr. Allen B. Cohen, and Dr. Martin A. Apple for their helpful review of this manuscript, and Miss Gisela L. Schanklies for her skillful technical assistance.

This work was supported in part by a grant from the U. S. Public Health Service, CA-11067, and by Cancer Research funds of the University of California.

\section{REFERENCES}

1. Lehrer, R. I., and M. J. Cline. 1969. Leukocyte myeloperoxidase deficiency and disseminated candidiasis: the role of myeloperoxidase in resistance to Candida infection. J. Clin. Invest. 48: 1478.

2. Lehrer, R. I., and M. J. Cline. 1969. Interaction of Candida albicans with human leukocytes and serum. $J$. Bacteriol. 98 : 996.

3. Lehrer, R. I. 1970. Measurement of candidacidal activity of specific leukocyte types in mixed cell populations. I. Normal, myeloperoxidase-deficient, and chronic granulomatous disease neutrophils. Infec. Immunity. 2: 42.

4. Lehrer, R. I., J. Hanifin, and M. J. Cline. 1969. Defective bactericidal activity in myeloperoxidase-deficient human neutrophils. Nature (London). 223: 78.

5. Schultz, J., and H. W. Shmukler. 1964. Myeloperoxidase of the leucocyte of normal human blood. II. Isolation, spectrophotometry, and amino acid analysis. Biochemistry. 3: 1234.

6. 1967. Peroxidase [horseradish]. donor: $\mathrm{H}_{2} \mathrm{O}_{2}$ oxidoreductase. I.U.B. 1.11.1.7. In Worthington Manual of Enzymes and Enzymes Reagents. Worthington Biochemical Corporation, Freehold, N. J.

7. Lehrer, R. I. 1969. Antifungal effects of peroxidase systems. J. Bacteriol. 99: 361.

8. Davis, W. B. 1942. Quantitative field test for estimation of peroxidase. Ind. Eng. Chem., Anal. Ed. 14: 952.

9. Pincus, S. H., and S. J. Klebanoff. 1971. Quantitative leukocyte iodination. N. Engl. J. Med. 284: 744.

10. Cohen, P. P. 1957. Suspending media for animal tissues In Manometric Techniques. W. W. Umbreit, R. H. Burris, and J. F. Stauffer, editors. Burgess Publishing Co., Minneapolis, Minn. 3rd edition. 149.

11. Klebanoff, S. J. 1970. Myeloperoxidase: contribution to the microbicidal activity of intact leukocytes. Science (Washington). 169: 1095

12. Klebanoff, S. J. 1967. Iodination of bacteria: a bactericidal mechanism. J. Exp. Med. 126: 1063.
13. Klebanoff, S. J. 1968. Myeloperoxidase-halide-hydrogen peroxide antibacterial system. J. Bacteriol. 95: 2131.

14. Paul, B. B., A. A. Jacobs, R. R. Strauss, and A. J. Sbarra. 1970. Role of the phagocyte in host-parasite interactions. XXIV. Aldehyde generation by the myeloperoxidase- $\mathrm{H}_{2} \mathrm{O}_{2}$-chloride antimicrobial system: a possible in vivo mechanism of action. Infec. Immunity. 2: 414.

15. Klebanoff, S. J. 1970. Myeloperoxidase-mediated antimicrobial systems and their role in leukocyte function. In Biochemistry of the Phagocytic Process: Localization and the Role of Myeloperoxidase and the Mechanism of the Halogenation Reaction. J. Schultz, editor. North-Holland Publishing Co., Amsterdam. 89.

16. Rosenberg, I. N. 1952. The antithyroid activity of some compounds that inhibit peroxidase. Science (Washington). 116: 503.

17. MacKenzie, C. G., and J. B. MacKenzie. 1943. Effect of sulfonamides and thioureas on the thyroid gland and basal metabolism. Endocrinology. 32: 185.

18. Carrara, G., and F. M. Chiancone. 1941. Sul meccanismo d'azione dei solfamidici. Nota III : primi dati sull'azione sulle redossasi. Chim. Ind. (Milan). 23: 435.

19. Lipmann, F. 1941. The oxidation of $p$-aminobenzoic acid catalyzed by peroxidase, and its inhibition by sulfanilamide. J. Biol. Chem. 139: 977.

20. Santarato, R. 1949. Azioni su alcuni enzimi delle sulfonamido-associazioni. Boll. Ist. Sieroter. Milan. 28: 317.

21. Saunders, B. C., A. G. Holmes-Siedle, and B. P. Stark. 1964. Peroxidase: The Properties and Uses of a Versatile Enzyme and of Some Related Catalysts. Butterworth \& Co. (Publishers) Ltd., London. 134.

22. Andrejew, A., Ch. Gernez-Rieux, and A. Tacquet. 1959. Inhibition de la peroxydase par l'hydrazide de l'acide isonicotinique (INH) et destruction de l'INH par la peroxydase. Bull. Soc. Chim. Biol. 41: 1047.

23. Rifkind, D., T. L. Marchioro, S. A. Schneck, and R. B. Hill, Jr. 1967. Systemic fungal infections complicating renal transplantation and immunosuppressive therapy: clinical, microbiologic, neurologic and pathologic features. Amer. J. Med. 43: 28.

24. Bodey, G. P. 1966. Fungal infections complicating acute leukemia. J. Chronic Dis. 19: 667.

25. Lehrer, R. I., and M. J. Cline. 1971. Leukocyte candidacidal activity and resistance to systemic candidiasis in patients with cancer. Cancer. 27: 1211.

26. Lehrer, R. I. 1970. Defective candidacidal activity of leukocytes from patients with systemic candidiasis. Clin. Res. 18: 443 . 